\title{
Elecro-organic Synthesis of Catecholthioethers
}

\author{
Davood Nematollahi* and Esmail Tammari \\ Department of Chemistry, Faculty of Science, University of Bu-Ali-Sina, Hamadan, \\ Zip Code 65174, Iran. E-Mail: nemat@basu.ac.ir, Fax: 0098 - 811-8272404, \\ Phone: 0098 - 811- 8271541
}

\section{Table of Contents:}

1. Compound 4a

1.1. ${ }^{1} \mathrm{H}$ NMR........... Page S2

1.2. ${ }^{13} \mathrm{C}$ NMR......... ..Page S3

1.3. M.S..................Page S4

1.4. IR................. Page S5

2. Compound $\mathbf{4 b}$

2.1. ${ }^{1}$ H NMR...............Page S6

2.2. ${ }^{13} \mathrm{C}$ NMR..............Page S7

2.3. M.S …........Page S8

2.4. IR................ Page S9

3. Compound 4c

3.1. ${ }^{1} \mathrm{H}$ NMR.............Page S10

1.1. ${ }^{13} \mathrm{C}$ NMR............Page S11

3.3. M.S ….......Page $\mathrm{S} 12$

3.4. IR................ Page S13

4. Compound 4d

4.1. ${ }^{1} \mathrm{H}$ NMR.............Page S14

4.2. ${ }^{13} \mathrm{C}$ NMR............Page S15

4.3. M.S ...........Page S16

4.4. IR............ Page S17 


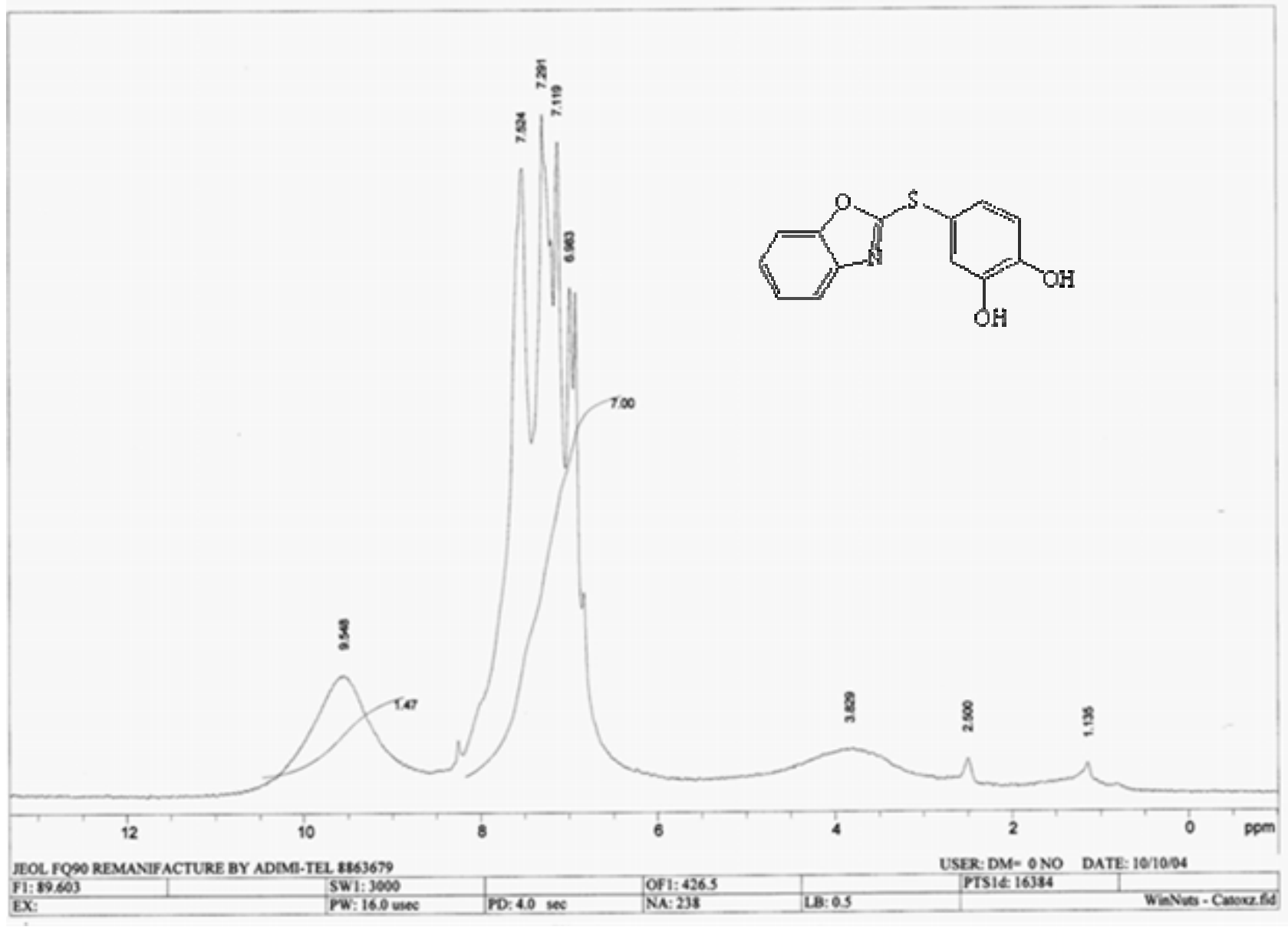

Compound 4a 


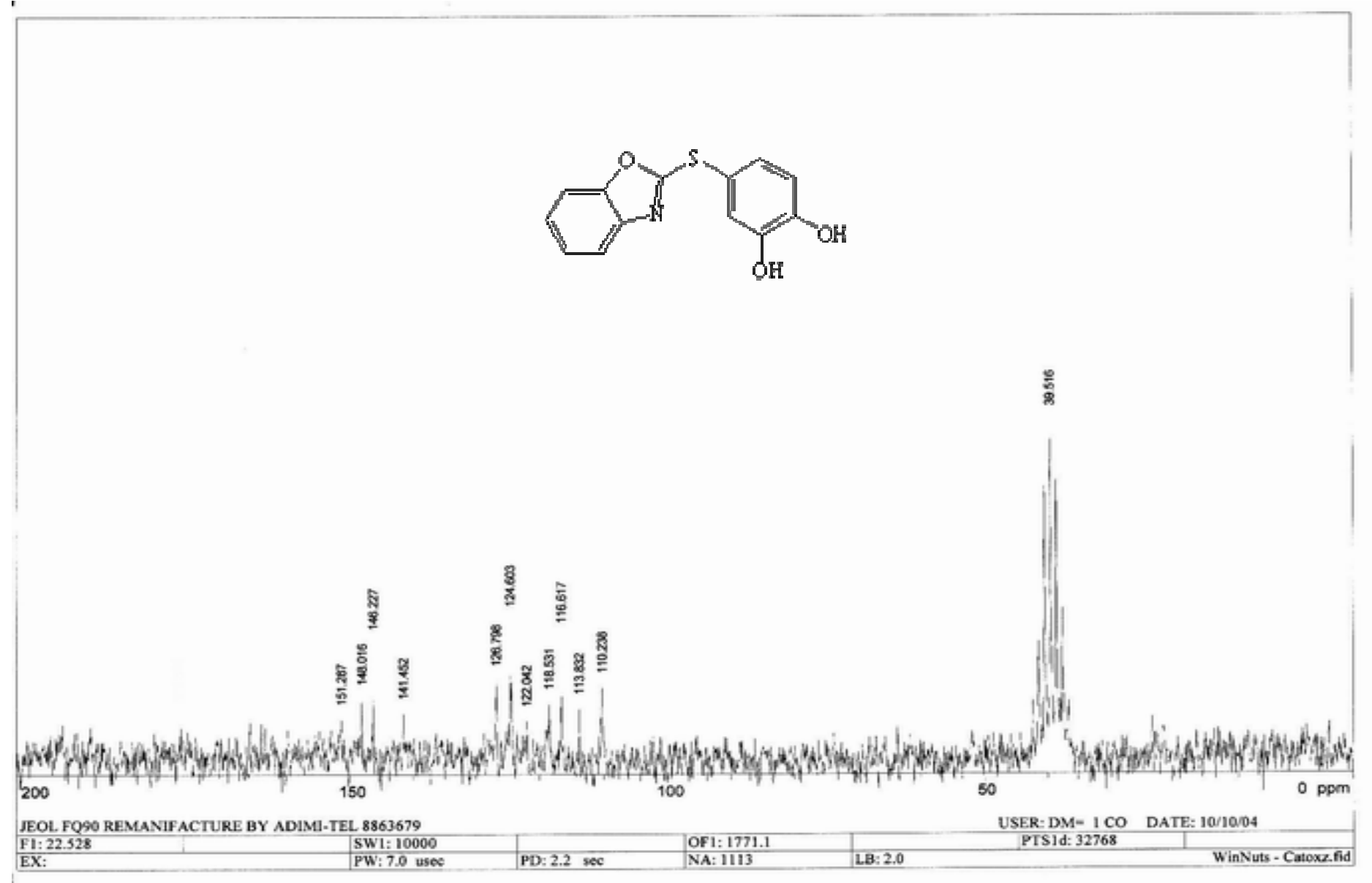

Compound 4a 


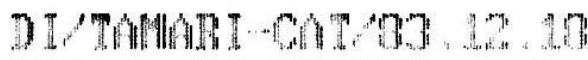

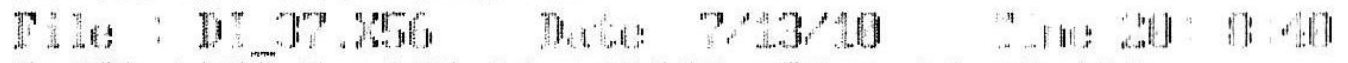
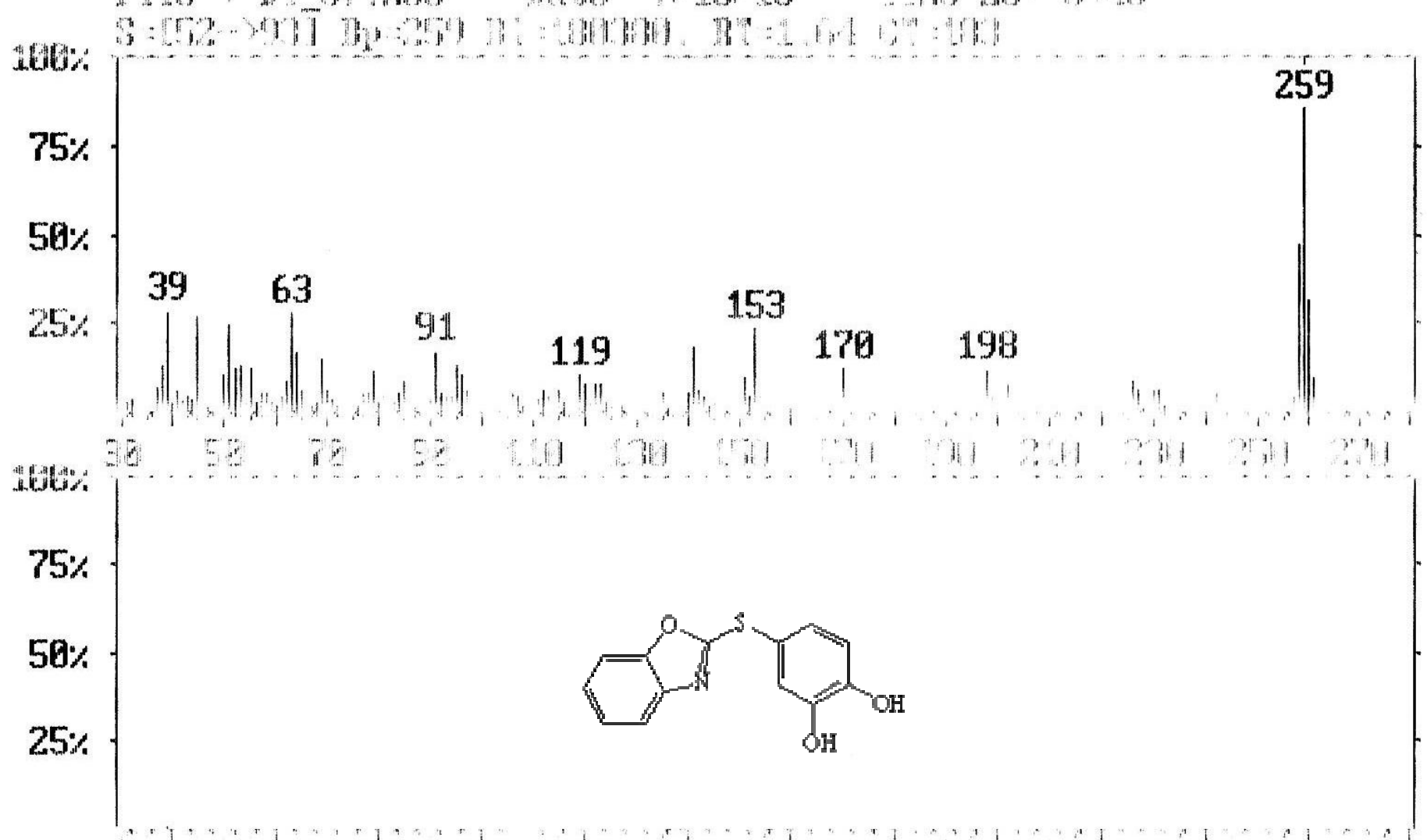

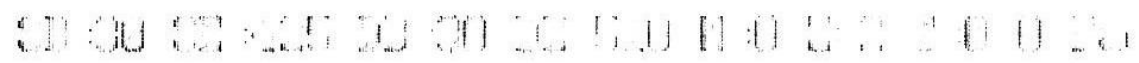

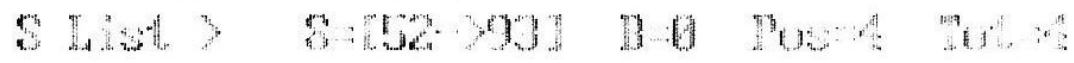


S5

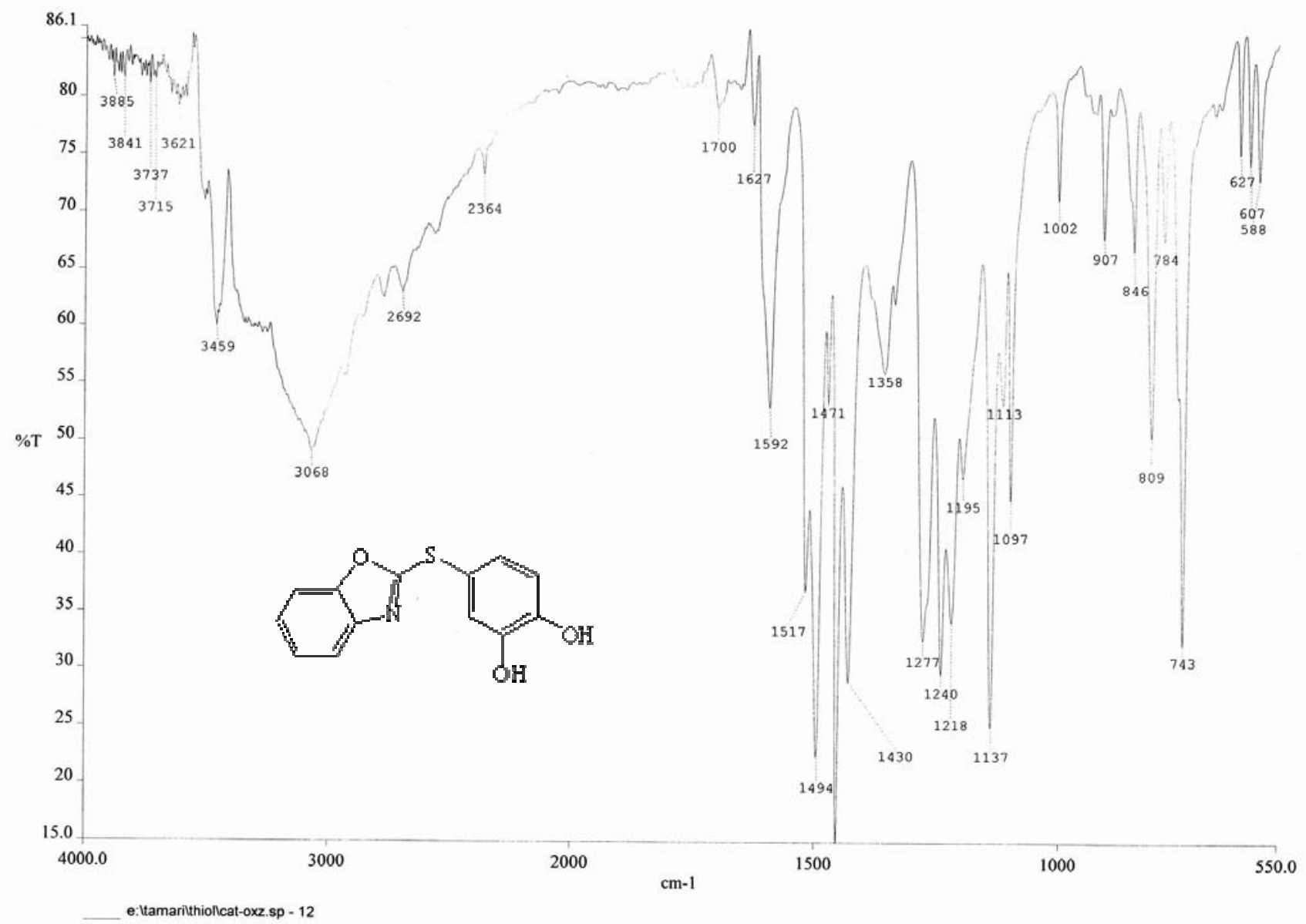

Compound 4a 


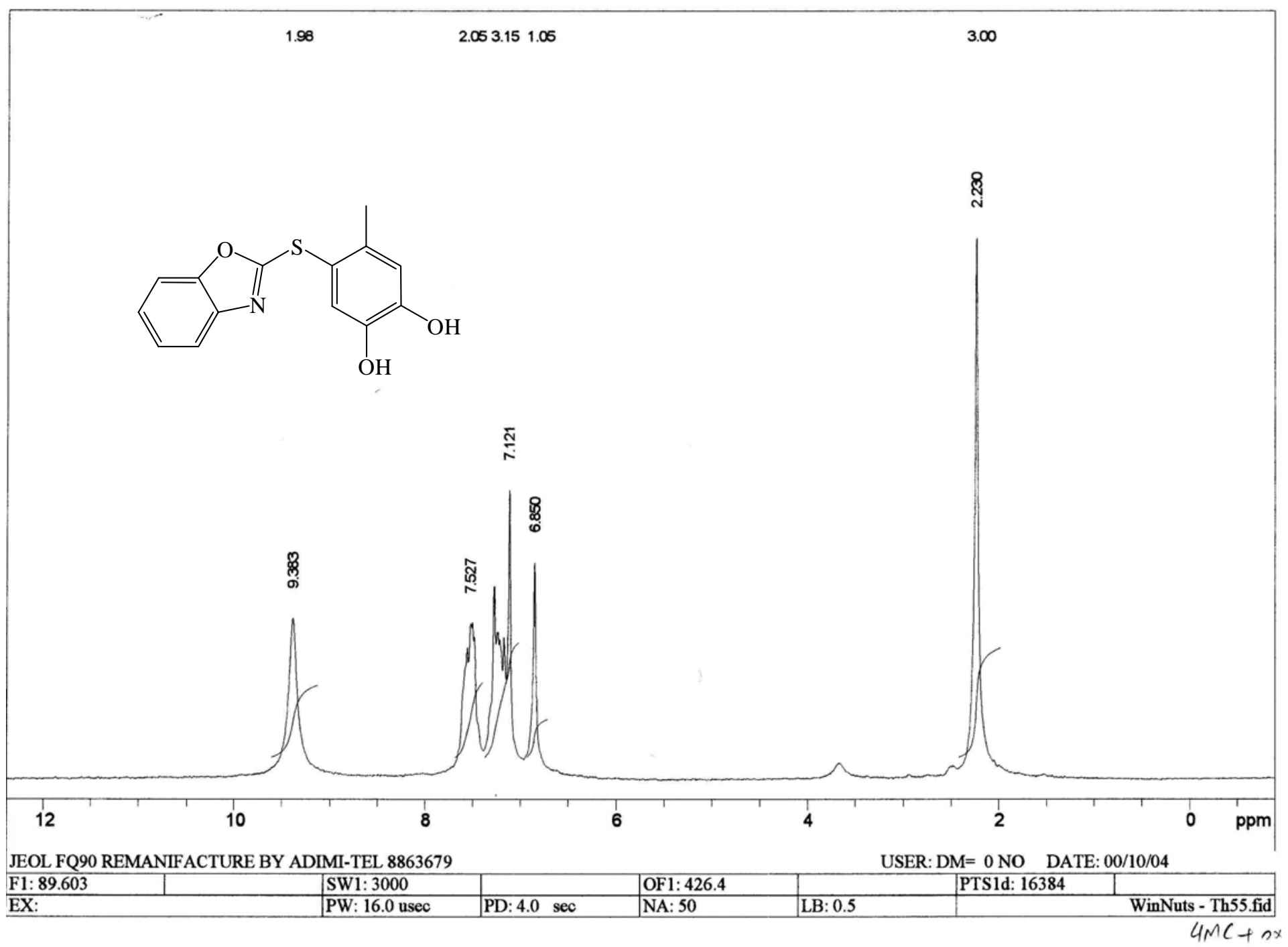

Compound 4b 


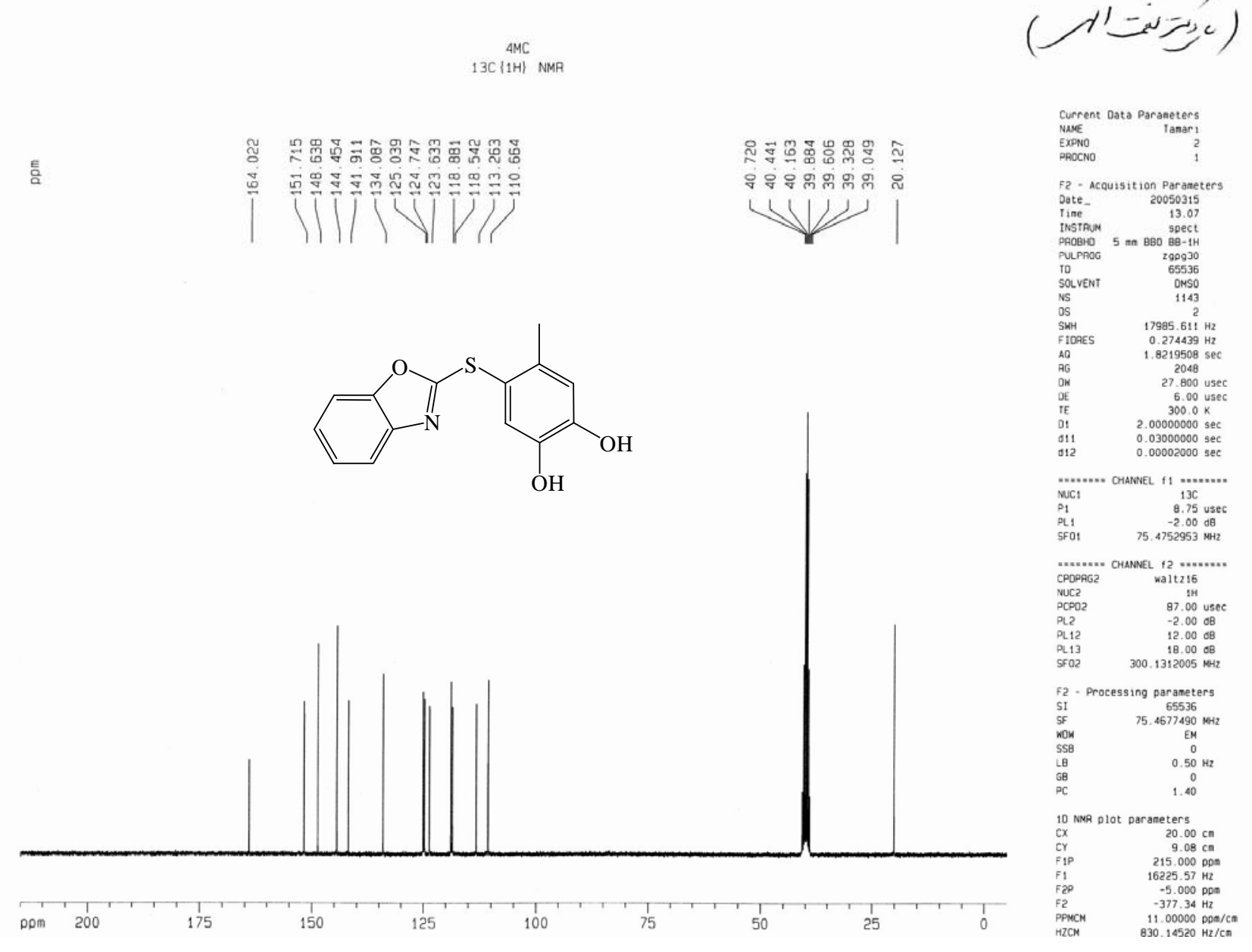

Compound 4b 


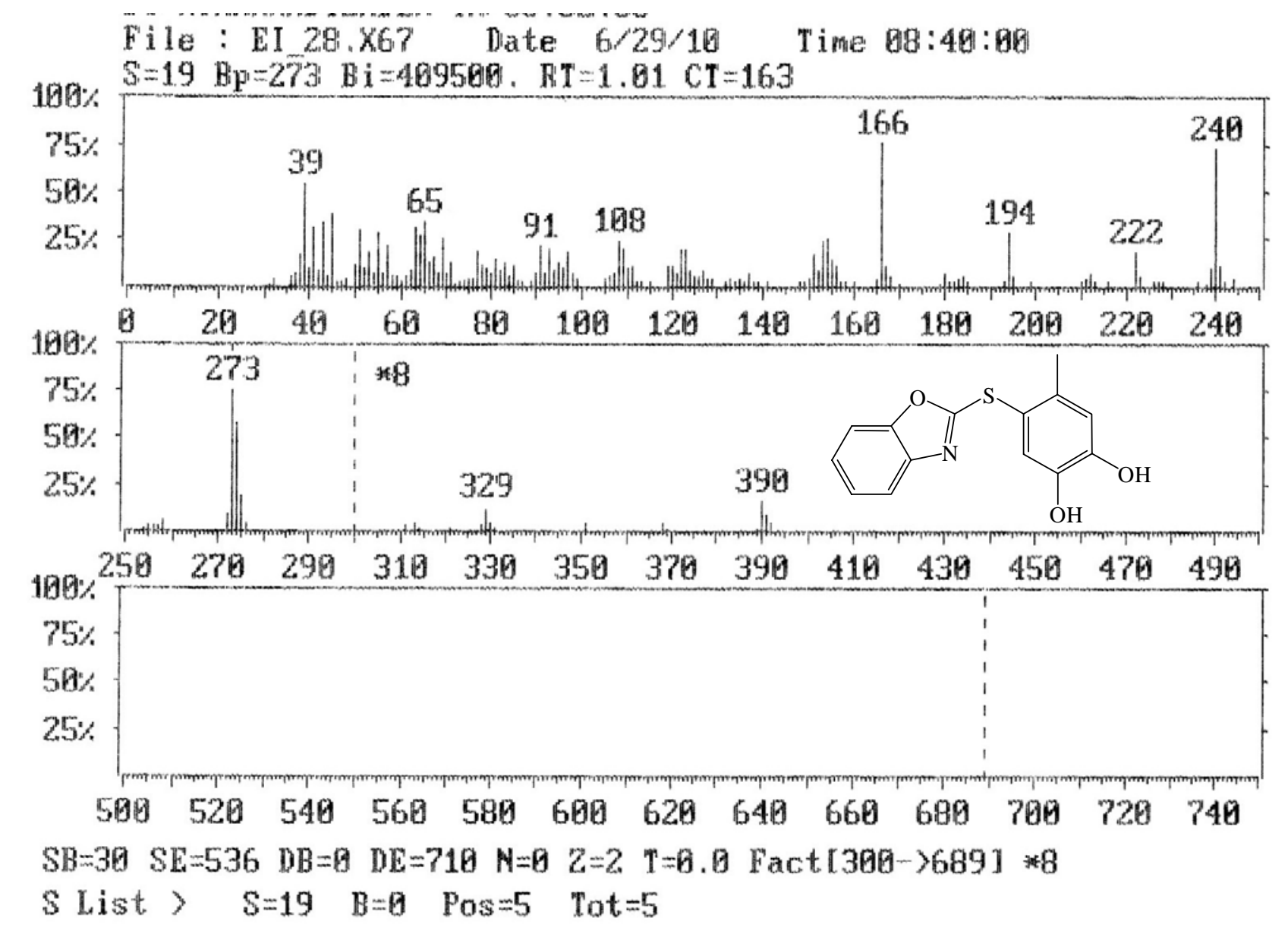

\section{Compound 4b}


S9

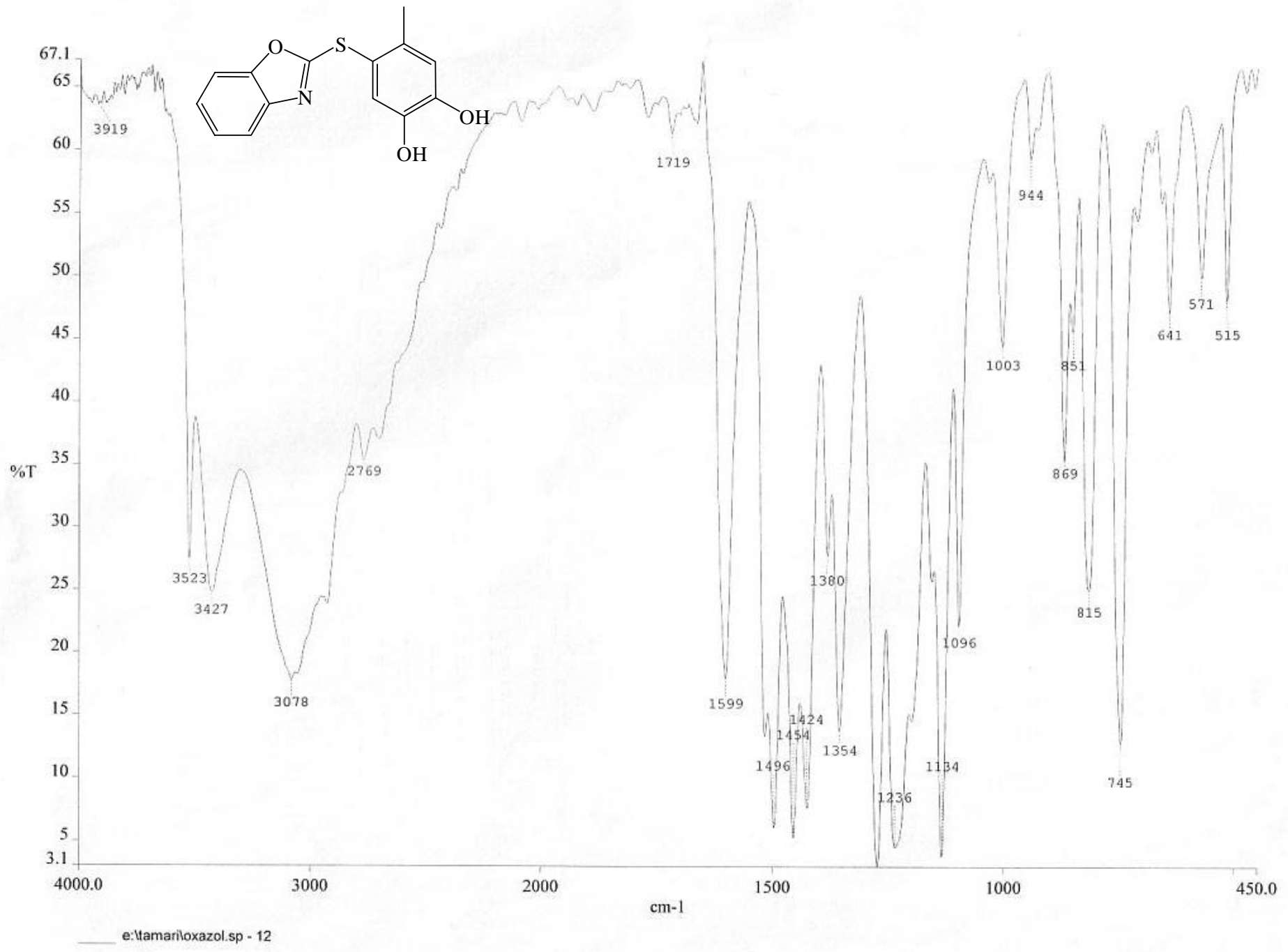




\section{Compound 4b}

S10

1.95

$\stackrel{\text { I }}{\stackrel{m}{+}}$<smiles>CC(C)(C)c1cc(O)c(O)cc1Sc1nc2ccccc2o1</smiles> 


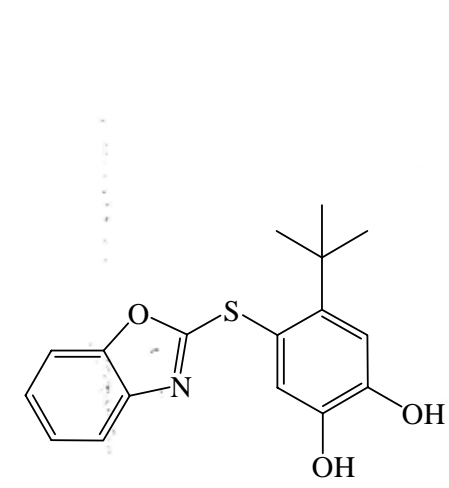

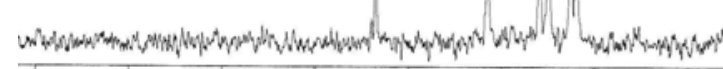

150

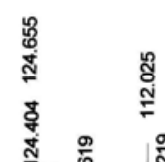

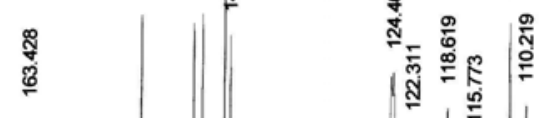

离萬

总离离

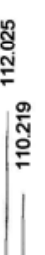

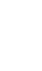

为

JEOL FQ90 REMANIFACTURE BY ADIMI-TEL 8863679 SW1: 10000 PW: 7.0 usec

\begin{tabular}{|l|l|l|}
\hline SW2: 0 & OF1: 1776.7 & OF2: 0.0 \\
\hline PD: $2.2 \mathrm{sec}$ & NA: 2500 & LB: 2.1
\end{tabular}

50

0 ppm

\begin{abstract}
EX:
F1: 22.528
\end{abstract}

PD: $2.2 \mathrm{sec}$

OF1: 1776

USER: $\mathrm{DM}=1 \mathrm{CO} \quad$ DATE: $10 / 30 / 04$ PTS1d: 65536

\title{
Compound 4c
}




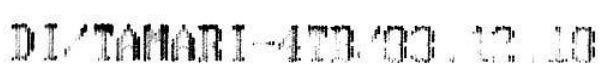

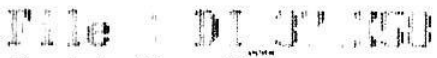

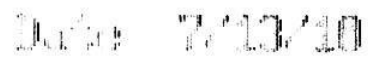

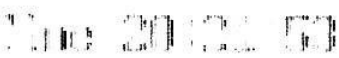

$166:$

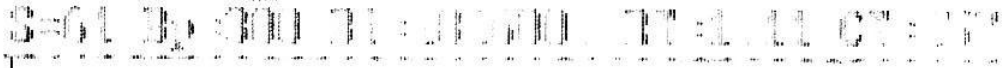

$75 \%$

$50 \%$

$25 \%$

39

63

152

91

$=1414,4,44,4$

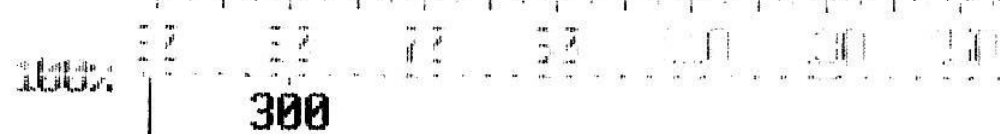

$75 \%$

$75 \%$
$50 \%$
$25 \%$

$75 \%$
$50 \%$
$25 \%$

3)

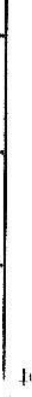

(1)

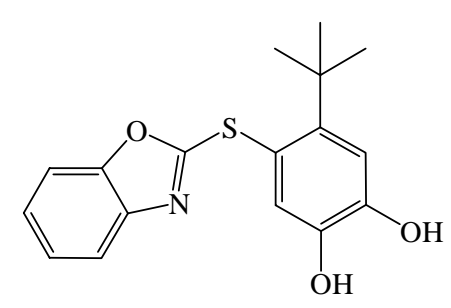

$5 \mathrm{~T}$

at. 30 . ve 5

Compound 4c 
S13

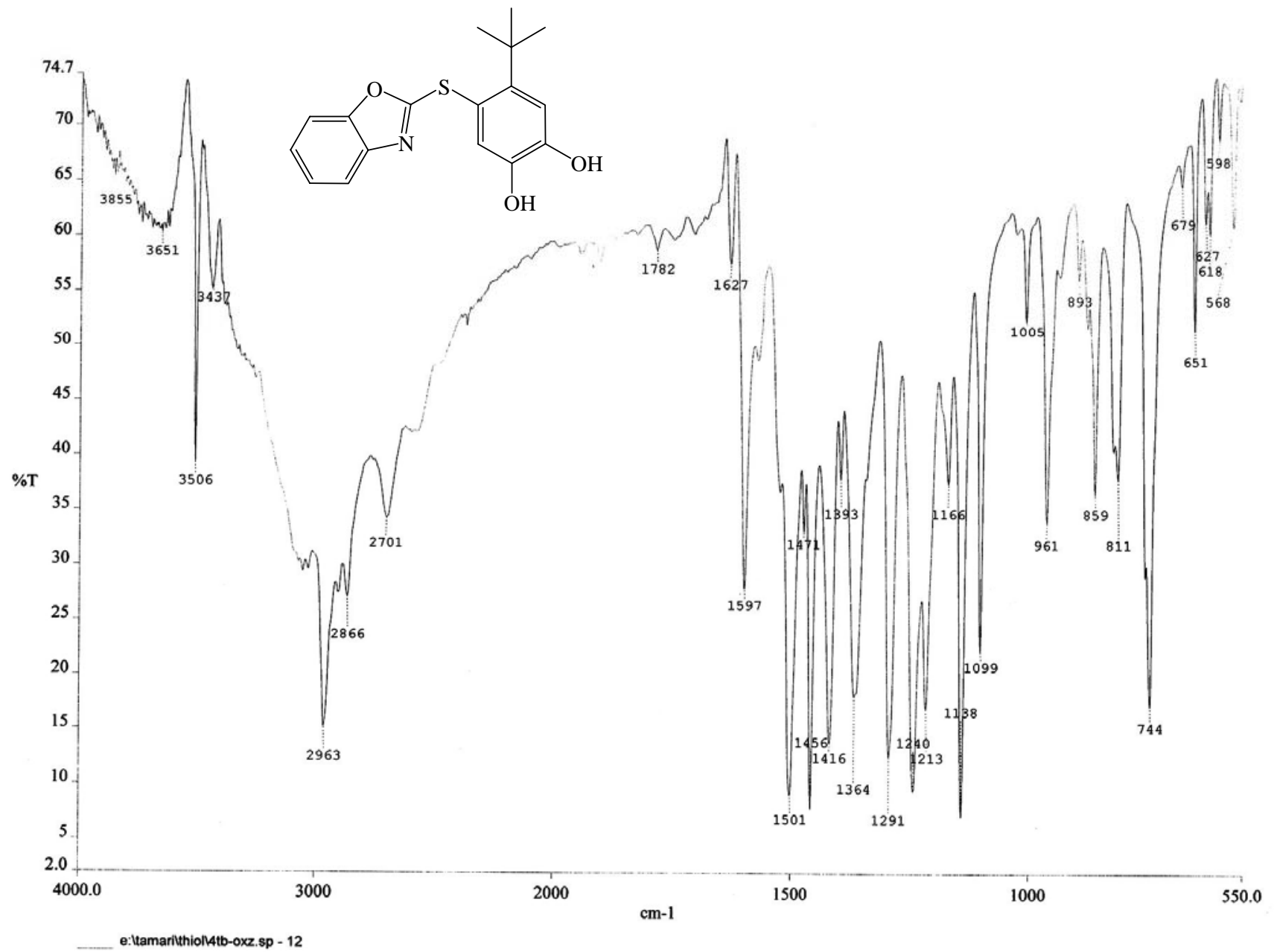

Compound 4c 
S14

2.23.281.99

6.37

3.00<smiles>COc1cc(Sc2nc3ccccc3o2)cc(O)c1O</smiles>

กิ

ํํำ

6

JEOL FQ90 REMANIFACTURE BY ADIMI-TEL 8863679 F1: 89.603 


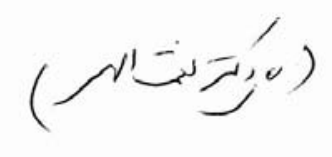

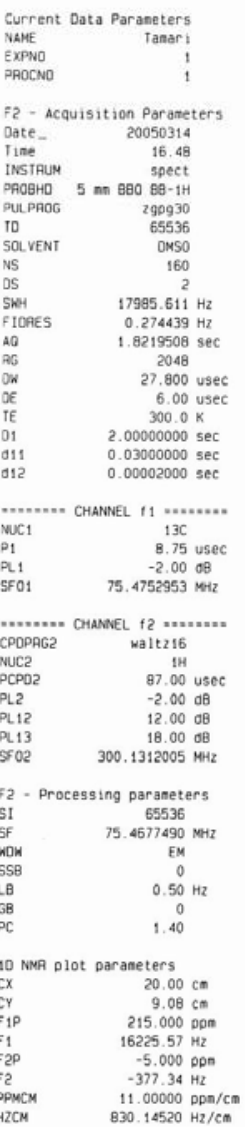

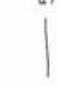
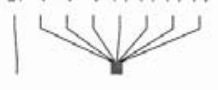

\section{Compound 4d}




\section{DI/TAMIARI-MIXXY/83,12.18}

\section{File: DI $37 . \times 59$ Date $7 / 13 / 10$ Thime $261: 28: 26$}
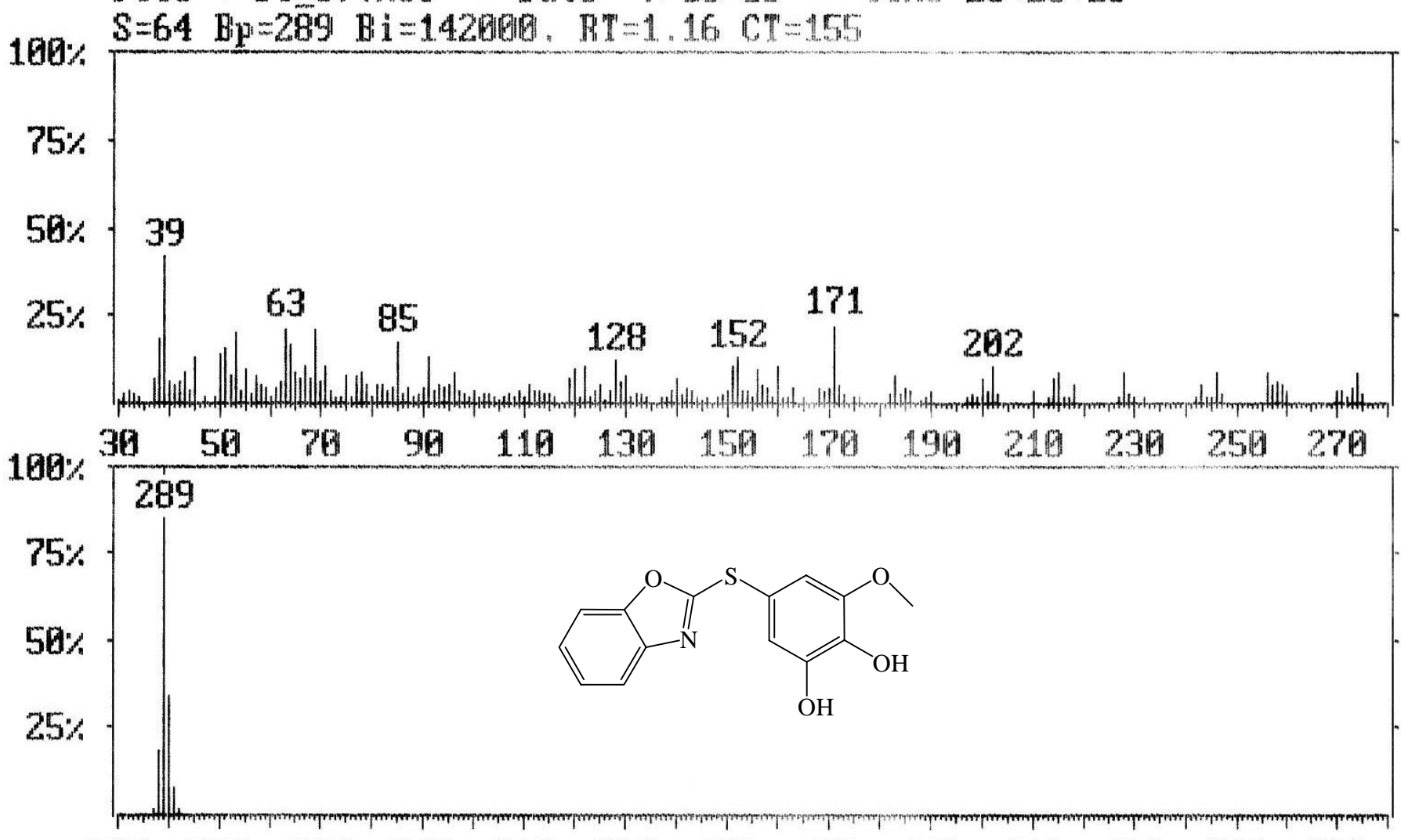

$\begin{array}{lllllllllllll}280 & 390 & 320 & 349 & 360 & 390 & 490 & 420 & 440 & 469 & 490 & 590 & 520\end{array}$

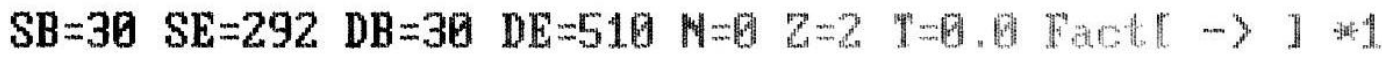
$S$ List > $S=64 \quad B=0 \quad P o s=6 \quad$ Tot $=6$

\section{Compound 4d}




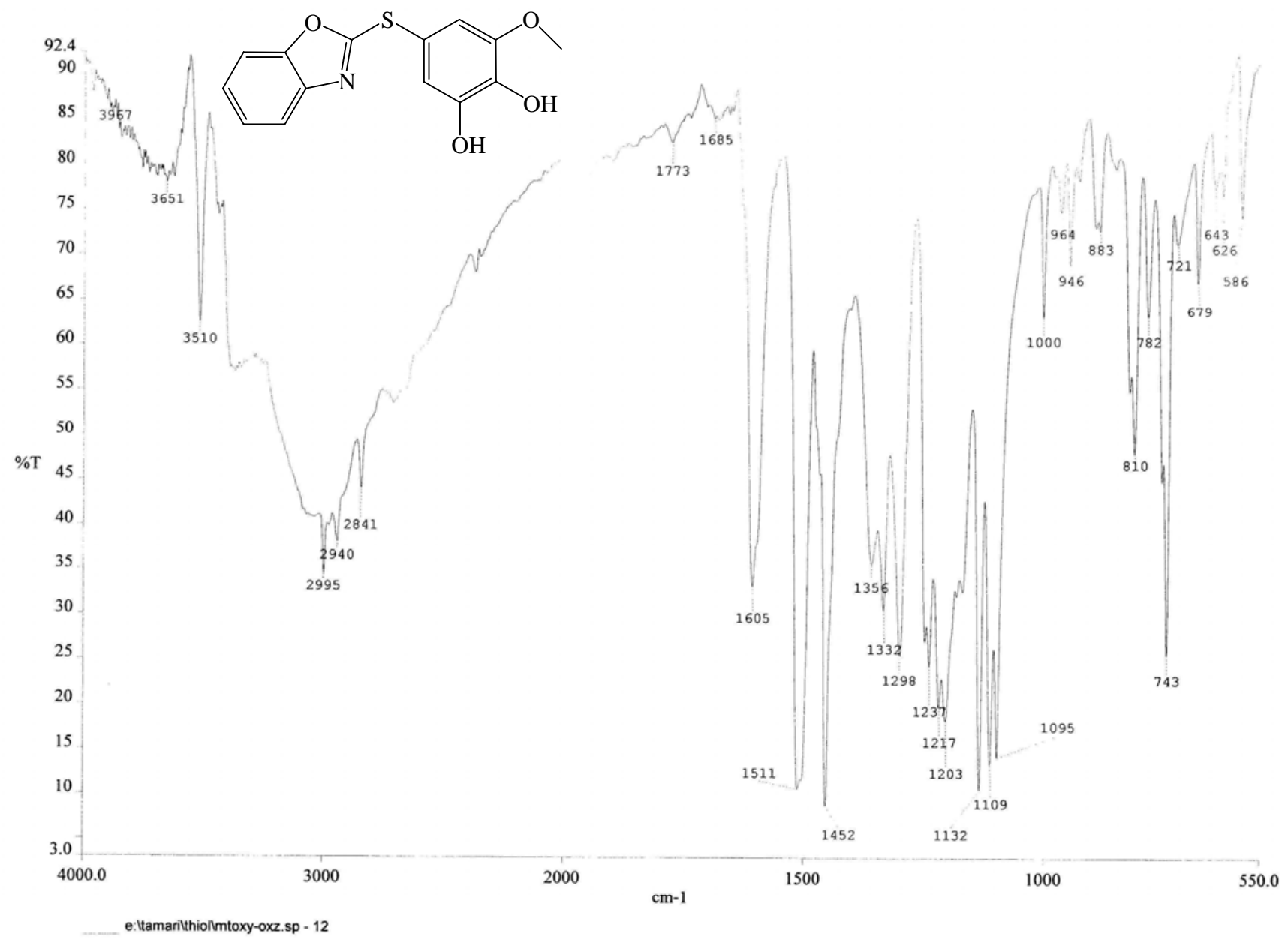

Compound 4d 